\title{
Is Mastectomy a Suitable Treatment in Ductal Carcinoma In Situ?
}

\author{
Paolo Veronesi ${ }^{1,2^{*}}$, Alessandra De Scalzi ${ }^{1}$ \\ 'IEO, European Institute of Oncology, IRCCS, Division of Breast Cancer Surgery, Milan, Italy \\ ${ }^{2}$ Faculty of Medicine, University of Milan, Milan, Italy
}

*Corresponding author: Professor Paolo Veronesi IEO, European Institute of Oncology IRCCS, Division of Breast Cancer Surgery, Milan, Italy E-Mail: paolo.veronesi@ieo.it

\begin{abstract}
Rezumat
În activitatea curentă a unui departament de senologie, este întâlnit din ce în ce mai frecvent diagnosticul de carcinom ductal in situ (CDIS). Carcinomul ductal in situ reprezintă un factor de risc pentru carcinomul mamar invaziv, iar un management corect al acestuia ar putea fi considerat un bonus pentru toți pacienții înscrişi în programele de screening. Tratamentul chirurgical al CDIS poate fi o provocare complexă, chiar mai mare decât carcinomul mamar invaziv; datele disponibile sunt foarte controversate şi o standardizare a practicii este necesară. În acest articol vă propunem o schemă practică folosită în cadrul Institutului Oncologic European din Milano pentru abordarea acestei teme complexe şi controversate.
\end{abstract}

Cuvinte cheie: carcinom ductal in situ

\section{Abstract}

In the current practice of a breast unit it is becoming more and more frequent to deal with the diagnosis of a ductal carcinoma in situ (DCIS). Ductal carcinoma in situ is a recognized risk factor for invasive breast carcinoma and a correct management could be considered as a reward for all the patients who apply regularly screening programs. The surgical management of DCIS can be a complex challenge even more than invasive carcinoma; available data is very controversial, and a standardization of practice is needed. Here we propose a practical flow chart used at the Oncologic European Institute in Milan to face this complex and controversial theme. 
Key words: ductal carcinoma in situ

\section{Introduction}

Ductal carcinoma in situ (DCIS), also referred to as intraductal carcinoma, is a non-invasive carcinoma of the breast.

The World Health Organization (WHO) define DCIS as "a neoplastic proliferation of epithelial cells confined to mammary ductallobular system and characterized by subtle to marked cytologic atypia and an inherent but not necessarily obligatory tendency to progression to invasive breast cancer" (1).

In the current practice, the management of DCIS continues to be challenging.

Thanks to the widespread of screening programs and sophisticated mammography the incidence of DCIS has risen through time.

DCIS is a known risk factor for invasive breast cancer, but the long-term cumulative risk is still unknown. An early recognition and an appropriate management of such lesions can help to prevent progression to invasive disease, and might, therefore, reduce breast cancer incidence, morbidity, and mortality.

DCIS lesions are routinely excised for therapeutic purposes following their detection. In a recent meta-analysis of 52 studies, invasive carcinoma was reported at final histopathological specimen in more than $1 / 4$ of cases (2).

The inability to reliably exclude the presence of invasive carcinoma after a core-biopsy diagnosis of DCIS, means that observation without excision is not considered as standard practice, except in patients with severe comorbidities.

Current surgical management options are disparate and include mastectomy, breastconserving surgery plus radiation therapy, or breast-conserving surgery alone (3).

The surgical strategy selection is determined by the extent of the DCIS lesion in relation to the size of the breast, to patient preference and pathologic findings. A detailed mammographic evaluation is essential to estimate the disease extend; usually, DCIS lesions are not clinically detectable. Holland et al. have described that the radiological evaluation of poorly differentiated DCIS is well related with microscopy assay. Conversely, the mammographic appearance of well-differentiated DCIS substantially underestimates the microscopic extent (4).

Thanks to the routine use of magnification views as part of the mammographic evaluation, the gap between imaging and pathological findings of low-grade DCIS is reduced.

In the imaging asset, the role of MRI in still uncertain. Even if some papers demonstrate a higher sensitivity of MRI in DCIS detection compared with mammography, no outcomes benefits have been described $(5,6)$.

\section{Breast Conservative Surgery}

The candidates to breast conservative surgery (BCS) are usually patients with a small solid mass, mammographically detected lesion, limited microcalcification areas, preferentially monocentric.

Preoperative radiologic localization should be used in most of the patients because usually the lesions are not palpable and associated with microcalcifications.

In our institute we used the radio guided occult lesion localization (ROLL 99m Tc) technique. A day before or on the day of surgery a dose of radioactive technetium-99 m nanocolloid is injected close to the marker placed at the biopsy time. After the injection, the right position of the trace is verified by a scintigraphy. Intraoperatively, a probe recognizes the trace and guides the surgeon to center the lesion.

There are two major challenges in choosing BCS for DCIS: obtaining negative specimen margins and identifying future local recurrence, especially an invasive one. The difficulties to obtain negative margins are due to 
DCIS's presentation. These lesions are typically vague masses, which often cannot be adequately seen or felt.

$\mathrm{Re}^{-}$excision is the treatment of "positive" or focally involved margins in DCIS. Results of the UK Sloane Project showed that in 30\% of patients undergoing BCS for DCIS, preoperative imaging underestimates the extent of disease resulting in a requirement for further surgery $(7,8)$.

In almost all the studies, margin status is reported to be related with the incidence of local recurrence; a reason should be the variability in specimen processing due to three-dimensional irregular specimen that makes data comparison very difficult. Even if close margins or positive margins, defined as ink on the tumor, are clearly associated with higher rates of local recurrence, the optimal width remains controversial. A meta-analysis of 22 studies including more than 4000 patients treated with surgery plus radiotherapy evaluated the impact of margins width. The risk of ipsilateral breast recurrence is related with margin status. The rate of local recurrence is lower with negative margins compared with uncertain or positive group. To date, there is no evidence that a margin wider than $2 \mathrm{~mm}$ lowers recurrence even in those patients treated also with RT (9).

A specific margin width that optimizes local control for those who do or do not receive RT has not been identified.

Data suggests that many are candidates for treatment with excision and irradiation, and a smaller group may be appropriately treated with excision alone. In a recent paper it is reported the 12 year rates of local recurrence for women with margin at least of $1 \mathrm{~cm}$ with surgery or surgery plus RT. The RT reduces the risk of local recurrence ( $14 \%$ for patients with excision alone VS $2.5 \%$ in patients with excision and RT) (10).

\section{Mastectomy}

Absolute indications for mastectomy include a diffuse multicentric finding, the presence of a large palpable mass or the malignant appearing microcalcifications covering an area impossible to excise obtaining clear margins with a good cosmetic result. A further indication to mastectomy is the persistence of tumor at resection margins after a reasonable number of surgical attempts.

If we assume that breast irradiation will be a part of the treatment, absolute contraindications to RT lead to mastectomy. Contraindications to RT, as for invasive cancer, include prior therapeutic irradiation to the ipsilateral breast, diagnosis early pregnancy, and active autoimmune diseases.

Theoretically, mastectomy should be $100 \%$ curative for pure DCIS; the reported local recurrence rates range from $1 \%$ to $3 \%$. Recurrence after mastectomy is usually invasive carcinoma and may present as either local recurrence or distant metastases without evidence of local recurrence. Breast cancerspecific survival rates at 10 years after mastectomy for DCIS are $\geq 98 \%$ (11).

In order to minimize the psychological and cosmetic impact of mastectomy, when the disease is not localized under the nipple areola complex or there is a nipple discharge, in our institute the first surgical choice is a nipple-sparing mastectomy. During surgery retro areolar tissue is checked by a frozen section.

\section{Axillary Management}

If the choice of the type of surgery on the breast in DCIS is debated, the axilla management is even more controversial. In front of a diagnosis of in situ carcinoma lymph nodes dissection should not be considered. However, there is a percentage of upstaging to invasive carcinoma that can be found at the final pathological diagnosis after surgery. Sentinel lymph node biopsy (SLNB) for some author should not be performed in DCIS patients (12), for others, SLNB should always be carried out $(13,14)$ and some others indicate the procedure just in selected cases.

In our center as in other cancer centers, the evaluation of sentinel lymph node is performed when the surgical choice is a mastectomy, since 
the disease is assumed to be extended, or when there are extended microcalcifications and/or multicentric lesions, in high grade lesions and when there is a palpable mass. All these presentations have a high risk of an infiltrating component at the final histopathological report.

\section{Discussion}

To improve the management of DCIS diagnosis in the surgical consultation and to standardize the approach in our Institute we published a decisional flow chart (Fig 1).

Facing this very debated theme it is necessary to facilitate the approach and tools such as algorithms are useful especially for less experienced breast surgeon.

In our flow chart it is underlined how the preference is still to save the breast when the cosmetic result is considered acceptable, involving plastic surgeons with the ability of utilizing level 2 oncoplastic techniques.

\section{Conclusions}

Breast-conserving surgery plus radiotherapy has been demonstrated to provide at least equivalent prognosis to mastectomy in invasive breast cancer.

Assuming the risk of metastatic disease for patients with DCIS is neglectable compared with invasive breast cancer, we could also take for granted that BCS should be considered safe for DCIS.

Mastectomy could be considered theoretically curative in all the cases but remains a radical approach to a lesion that usually does not progress to invasive cancer in most patients. Compared with BCS, removing all the breast tissue means higher complication rates, longer hospital stays and rehabilitation time both physical and psychological.

Mastectomy still remains the only possible strategy in some extended and multifocal DCIS or in patients with a strong will.

Assuming the risk of re- excision and the

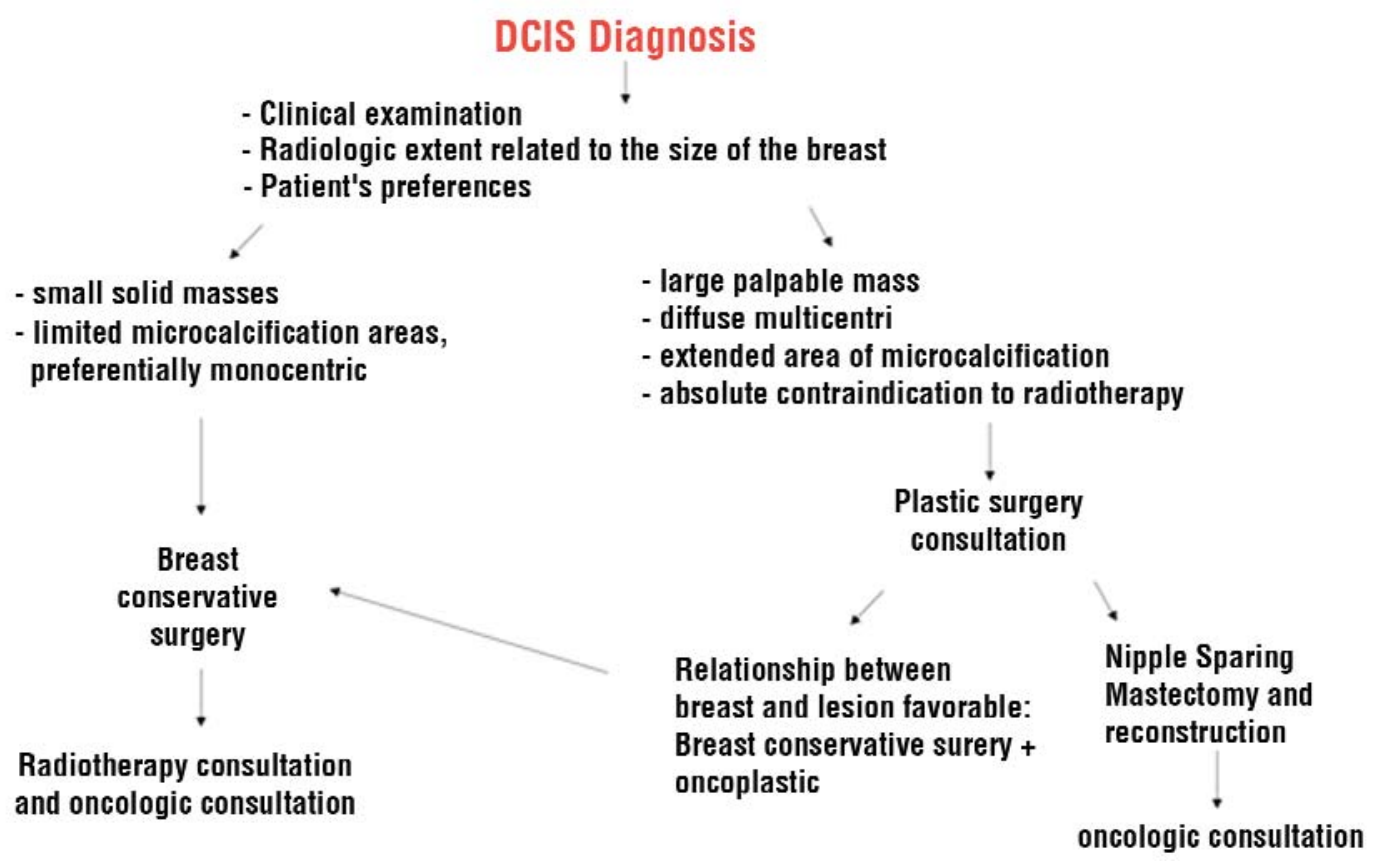

Figure 1. Flowchart of surgical strategy in DCIS 
risk of local recurrence, BCS is effective and appropriate for the treatment of DCIS and an internal guideline is a useful tool to support this choice.

\section{References}

1. Lakahni S.R. WHO Classification of Tumours of the Breast. 4.a ed , 2012

2. Brennan ME, Turner RM, Ciatto S, Marinovich ML, French JR, Macaskill P, et al. Ductal carcinoma in situ at core-needle biopsy: meta-analysis of underestimation and predictors of invasive breast cancer. Radiology. 2011; 260(1):119-28

3. Morrow M, Schnitt JS, Norton L. Current management of lesions associated with an increased risk of breast cancer. Nat Rev Clin Oncol. 2015; 12(4):227-38.

4. Holland R, Hendriks JH, Vebeek AL, Mravunac M, Schuurmans Stekhoven $\mathrm{JH}$. Extent, distribution, and mammographic/histological correlations of breast ductal carcinoma in situ. Lancet. 1990;335(8688):519-22.

5. Bluemke DA, Gatsonis CA, Chen MH, DeAngelis GA, DeBruhl N, Harms S, et al. Magnetic resonance imaging of the breast prior to biopsy. JAMA. 2004;292(22):2735-42.

6. Berg WA, Zhang Z, Lehrer D, Jong RA, Pisano ED, Barr RG, et al. Detection of breast cancer with addition of annual screening ultrasound or a single screening MRI to mammography in women with elevated breast cancer risk.
JAMA. 2012:307(13):1394-404.

7. Farante G, Zurrida S, Galimberti V, Veronesi P, Curigliano G, Luini A, et al. The management of ductal intraepithelial neoplasia (DIN): open controversies and guidelines of the Istituto Europeo di Oncologia (IEO), Milan, Italy. Breast Cancer Res Treat. 2011;128(2):369-78.

8. Thomas J, Evans A, Macartney J, Pinder SE, Hanby A, Ellis I, et al. Radiological and pathological side estimations of pure ductal carcinoma in situ of the breast: a review of 2564 cases from the Sloane Project. $\mathrm{Br} \mathrm{J}$ Cancer. 2010;102(2):285-93.

9. Dunne C, Burke JP, Morrow M, Kell MR. Effect of margin status on local recurrence after breast conservation and radiation therapy for ductal carcinoma in situ. J Clin Oncol 2009;27(10):1615-20.

10. Macdonald HR, Silverstein MJ, Lee LA, Ye W, Sanghavi P, Holmes DR, et al. Margin width as the sole determinant of local recurrence after breast conservation in patients with ductal carcinoma in situ of the breast. Am J Surg. 2006;192(4):420-2.

11. Kelley L, Silverstein M, Guerra L. Analyzing the risk of recurrence after mastectomy for DCIS: a new use for the USC/Nan Nuys Prognostic Index. Ann Surg Oncol. 2011;18(2):459-62. Epub 2010 Sep 22.

12. Edge SB, Sheldon DG. Counterpoint: sentinel lymph node biopsy is not indicated for ductal carcinoma in situ. J Natl Compr Canc Netw. 2003;1(2): 207-12.

13. Pendas S, Dauway E, Giuliano R, Ku N, Cox CE, Reintgen DS. Sentinel node biopsy in ductal carcinoma in situ patients. Ann Surg Oncol. 2000;7(1):15-20.

14. Ansari B, Ogston SA, Purdie CA, Adamson DJ, Brown DC, Thompson AM. Meta-analysis of sentinel node biopsy in ductal carcinoma in situ of the breast. Br J Surg. 2008;95(5):547-54. 